\title{
Relação entre características morfológicas da cariopse e fusariose em milho(1)
}

\author{
Raquel Silva Costa(2), Fabíola Vitti Môro(2), José Roberto Môro(2), Herberte Pereira da Silva(2) e Rita de Cássia Panizzi(3)
}

\begin{abstract}
Resumo - Fusarium moniliforme causa sérios prejuízos no rendimento do milho. Suspeita-se que a entrada do fungo na cariopse ocorra pela cicatriz do estilete, e que este fato e o nível de infestação por F. moniliforme estejam relacionados com características morfológicas da cariopse. O objetivo deste trabalho foi identificar características morfológicas que conferem resistência a F. moniliforme em cariopses de milho. Cariopses de seis linhagens de milho, com e sem inoculação do patógeno, foram avaliadas utilizando-se de estereomicroscópio e o microscópio eletrônico de varredura. Características morfológicas da cariopse, tais como: tegumento com saliências e reentrâncias acentuadas, pericarpo pouco espesso, amido menos compacto e presença do canal estilar favorecem a penetração de F. moniliforme.
\end{abstract}

Termos para indexação: Zea mays, Fusarium moniliforme, infestação, microscopia, morfologia vegetal.

\section{Relationship between caryopsis morphological characteristics and fusarium ear rot in corn}

\begin{abstract}
Fusarium ear rot of corn caused by Fusarium moniliforme is responsible for severe yield losses. Probably fungal penetration in the caryopsis takes place at the silk scar and is related to the level of infection and the morphological characteristics of the caryopsis. The objective of this work was to identify morphological characteristics that confer resistance to the fungus in caryopsis of corn. Caryopsis of six lines of corn, with and without inoculation with the pathogen, were evaluated using a stereomicroscope and scanning electron microscope. Morphological characteristics of the caryopsis such as tegument with saliences and reentrances accentuated, pericarp no much thick, starch less compact and presence of the silk canal favor the penetration of F. moniliforme.
\end{abstract}

Index terms: Zea mays, Fusarium moniliforme, infestation, microscopy, plant morphology.

\section{Introdução}

O milho (Zea mays L.), em razão de seu potencial produtivo, composição química e valor nutritivo, constitui-se um dos mais importantes cereais cultivados e consumidos no mundo. Por causa da sua multiplicidade de aplicações, tanto na alimentação humana como animal, tem relevante papel socioeconômico, além de ser matéria prima básica para diversificados complexos agroindustriais (Fancelli \& Dourado Neto, 2000).

\footnotetext{
${ }^{(1)}$ Aceito para publicação em 28 de agosto de 2002.

Extraído da dissertação de mestrado apresentada pela primeira autora à Universidade Estadual Paulista (Unesp), Jaboticabal, SP.

(2)Unesp, Dep. de Biologia Aplicada à Agropecuária, Via de Acesso Prof. Paulo Donato Castellane, s/no, CEP 14884-900 Jaboticabal, SP. E-mail: rscosta@fcav.unesp.br, fabiola@fcav.unesp.br, jrmoro@fcav.unesp.br, hpdasilva@uol.com.br

(3)Unesp, Dep. de Fitossanidade. E-mail: rpanizzi@ fcav.unesp.br
}

Nas condições edafoclimáticas das regiões de cultivo dessa gramínea no Brasil, entre os principais fungos que infestam as cariopses do milho, em condições de campo de produção, está o Fusarium moniliforme Sheldon, causador da podridão-da-espiga (Pinto, 1998).

A produção de várias substâncias pelo gênero Fusarium, como ácido fusárico, fusarinas, giberelinas, moniliforminas e fumonisinas, aumenta sua importância como patógeno de milho (Kucharek \& Kommedahl, 1966; Nelson, 1992; Munkvold \& Desjardins, 1997; Pereira, 1997). Essas toxinas, além de prejudiciais à planta, podem causar doenças no homem e animais que consumirem o milho contaminado.

O melhoramento genético por meio da seleção de plantas resistentes a doenças, mais o avanço da genética e da fitopatologia, além de eficiente e econômico, muitas vezes dispensa o emprego de defensivos agrícolas, contribuindo, assim, para a preservação do meio ambiente. 
Se as características morfológicas das cariopses estiverem relacionadas à resistência ao F. moniliforme, poderão ser empregadas em programas de melhoramento genético do milho e na identificação de genótipos resistentes a essa doença.

O objetivo deste trabalho foi identificar características morfológicas que conferem resistência a F. moniliforme em cariopses de milho.

\section{Material e Métodos}

O trabalho foi realizado no Departamento de Biologia Aplicada à Agropecuária da Faculdade de Ciências Agrárias e Veterinárias, Unesp, Campus de Jaboticabal. Foram utilizadas seis linhagens de milho, sendo três com textura de milho do tipo flint: LJRM 1048, suscetível ao F. moniliforme (FS); LJRM 2494, resistente (FR); LJRM 910, intermediária (FI), e três com textura de milho do tipo dentado: LJRM 960, suscetível ao fungo (DS); LJRM 1554, resistente (DR); e LJRM 1419, intermediária (DI).

Uma amostra de 20 cariopses de cada uma das seis linhagens foi utilizada para observação e documentação em microscopia eletrônica de varredura. Dez cariopses foram cortadas ao meio, no sentido longitudinal, para documentação interna, e outras dez foram observadas externamente, na região da cicatriz do estilete. As cariopses foram lavadas em acetona por 30 segundos e montadas sobre porta-espécimens cilíndricos metálicos de, aproximadamente, $10 \mathrm{~mm}$ de diâmetro por $10 \mathrm{~mm}$ de altura. $\mathrm{Na}$ fixação sobre os cilindros, foram utilizadas fitas adesivas e, posteriormente, foi aplicada pasta condutiva de carbono sobre as bordas da fita adesiva, para neutralização da ação isolante. As amostras foram cobertas com uma camada de ouro de $35 \mathrm{~nm}$, em metalizador, e observadas ao microscópio eletrônico de varredura, operado a $15 \mathrm{kV}$.

Nas cariopses cortadas longitudinalmente foram feitas micrografias eletrônicas da camada do pericarpo e do amido constituinte do endosperma, nas regiões de amido poroso (amido branco) e nas de mais compacto (amido amarelo). A espessura do pericarpo foi mensurada no ponto médio da região superior da cariopse. Nas dez cariopses inteiras, foram observadas e documentadas a região de cicatriz do estilete e do tegumento próximo a ela.

As cariopses de milho receberam inóculo de um isolado de F. moniliforme obtido de cariopse de milho naturalmente infectada e com sintomas típicos de fusariose.

A inoculação nas seis linhagens de milho foi feita em seis tempos de exposição (contato) ao fungo, o qual foi anteriormente cultivado em placas de Petri contendo o meio de cultura ágar, batata, dextrose (BDA).
O delineamento experimental foi inteiramente casualizado, com 36 tratamentos (seis linhagens x seis períodos de exposição das cariopses ao patógeno) e três repetições. Cada repetição foi representada por uma cariopse, e os seis períodos de exposição foram: 0 (testemunha), 2, 4, 8, 16 e 48 horas. Os dados da espessura da cariopse das linhagens de milho foram submetidos à análise de variância e as médias comparadas pelo teste de Tukey a $5 \%$ de probabilidade.

Após inoculação, as cariopses foram submetidas aos processos de fixação (glutaraldeído a $3 \%$ em tampão fosfato e tetróxido de ósmio a $2 \%$ em tampão fosfato por, aproximadamente, 90 minutos), desidratação (série gradual em álcool etílico: 30\%, 50\%, 70\%, 80\%, 90\%, e $100 \%$, com dez minutos de exposição em cada solução, em temperatura ambiente, repetindo o último passo) e secagem (secador de ponto crítico, modelo EMS 850) das cariopses como método de preparação para observação ao microscópio eletrônico de varredura.

Foram montadas 36 cariopses (seis linhagens $\mathrm{x}$ seis períodos de exposição), em corte longitudinal, e 36 cariopses inteiras nos porta-espécimens, metalizadas e observadas externamente, na região da abertura do canal estilar.

\section{Resultados e Discussão}

A compactação do endosperma na região do amido amarelo e branco é maior nas linhagens resistentes, tanto flint como dentado. Essa característica confere maior dureza ao endosperma e pode ter influência na infestação do fungo (Figuras 1 e 2).

As linhagens dentado suscetível (DS) e dentado intermediária (DI) apresentaram a espessura do pericarpo significativamente menor que as demais, as quais não diferiram entre si (Tabela 1, Figura 3).

Scott \& King, citados por Hoenisch \& Davis (1994), mostraram que a resistência à podridão-daespiga é dominada pelo controle genético do órgão feminino da planta, sendo coerente com a relação entre palhas firmes e alta resistência. Assim, os mesmos autores sugeriram que o local de resistência pode ser o pericarpo das cariopses, o qual também possui tecido maternal.

Examinando a espessura do pericarpo e camada de aleurona de cariopses de híbridos de milho, utilizando lâminas histológicas, Hoenisch \& Davis (1994) observaram, por medições em microscópio óptico com escala micrométrica, que a espessura do 


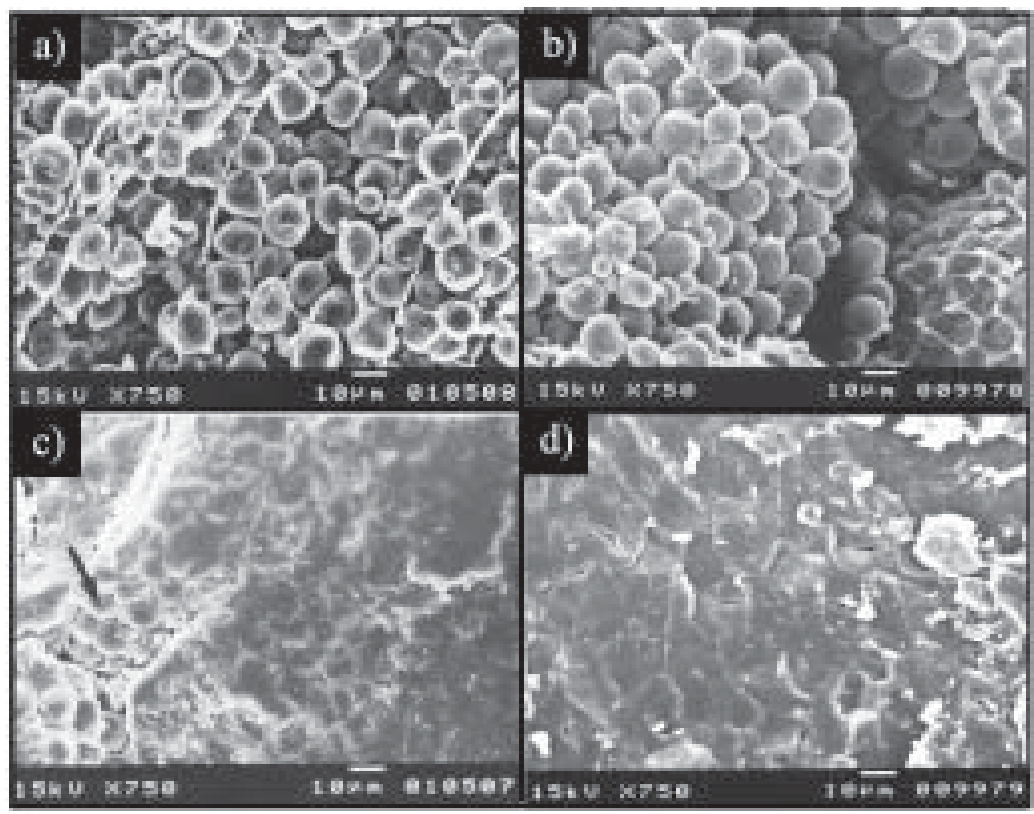

Figura 1. Eletromicrografias de varredura de cariopses de milho evidenciando: a) amido branco da linhagem flint suscetível; b) amido branco da linhagem flint resistente; c) amido amarelo da linhagem flint suscetível; d) amido amarelo da linhagem flint resistente. Porosidade $(\rightarrow)$. Barra $=10 \mu \mathrm{m}$.

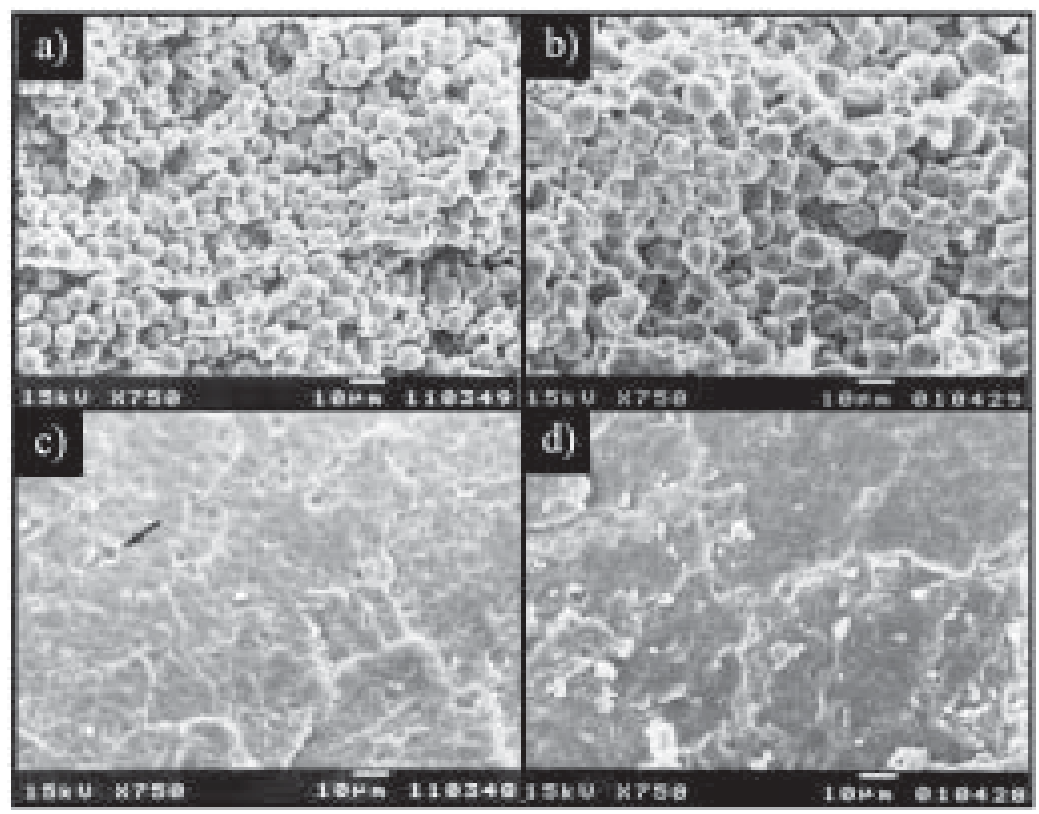

Figura 2. Eletromicrografias de varredura de cariopses de milho evidenciando: a) amido branco da linhagem dentado suscetível; b) amido branco da linhagem dentado resistente; c) amido amarelo da linhagem dentado suscetível; d) amido amarelo da linhagem dentado resistente. Porosidade $(\rightarrow)$. Barra $=10 \mu \mathrm{m}$. 
pericarpo de grupos de híbridos resistentes e intermediários foi significativamente maior que a de híbridos suscetíveis. Os híbridos suscetíveis e com pericarpos menos espessos que os dos híbridos intermediários e resistentes foram severamente infectados com $F$. moniliforme.

Tabela 1. Espessura do pericarpo de cariopses de seis linhagens de milho ${ }^{(1)}$.

\begin{tabular}{lc}
\hline Linhagens & $\begin{array}{c}\text { Espessura } \\
\text { média }(\mu \mathrm{m})\end{array}$ \\
\hline LJRM 960 (dentado suscetível) & $22,921 \mathrm{~b}$ \\
LJRM 1419 (dentado intermediária) & $20,222 \mathrm{~b}$ \\
LJRM 1554 (dentado resistente) & $29,222 \mathrm{a}$ \\
LJRM 1048 (flint suscetível) & $30,623 \mathrm{a}$ \\
LJRM 910 (flint intermediária) & $29,887 \mathrm{a}$ \\
LJRM 2494 (flint resistente) & $30,712 \mathrm{a}$ \\
\hline Média geral & 27,2645 \\
\hline (1)Médias seguidas de mesma letra, na coluna, não diferem entre si pelo \\
teste de Tukey a 5\% de probabilidade; o coeficiente de variação foi \\
de 11,72\%.
\end{tabular}

A superfície do pericarpo próximo à região da cicatriz do estilete nas linhagens suscetíveis possuía saliências e reentrâncias mais acentuadas que nas resistentes (Figura 4). Essa característica facilitou a fixação das hifas do fungo sobre a cariopse (Figura 5).

Hoenisch \& Davis (1994) afirmam que todas as partes do pericarpo nos estádios tardios de desenvolvimento da cariopse são compostas de células mortas que são tubos celulósicos. Os encaixes e arranjos dessas células com paredes espessas causam considerável resistência do pericarpo. Um pericarpo fino pode permitir ao fungo maior acesso à cariopse, através de ferimentos causados por insetos durante a alimentação.

Nas eletromicrografias da região da abertura do canal estilar, observou-se que a maioria das cariopses das linhagens de milho dentado suscetível (DS), dentado intermediária (DI) e flint suscetível (FS) apresentaram o canal (Figura 6), ao contrário da maioria das cariopses das linhagens dentado resistente (DR), flint intermediária (FI) e flint resistente (FR).

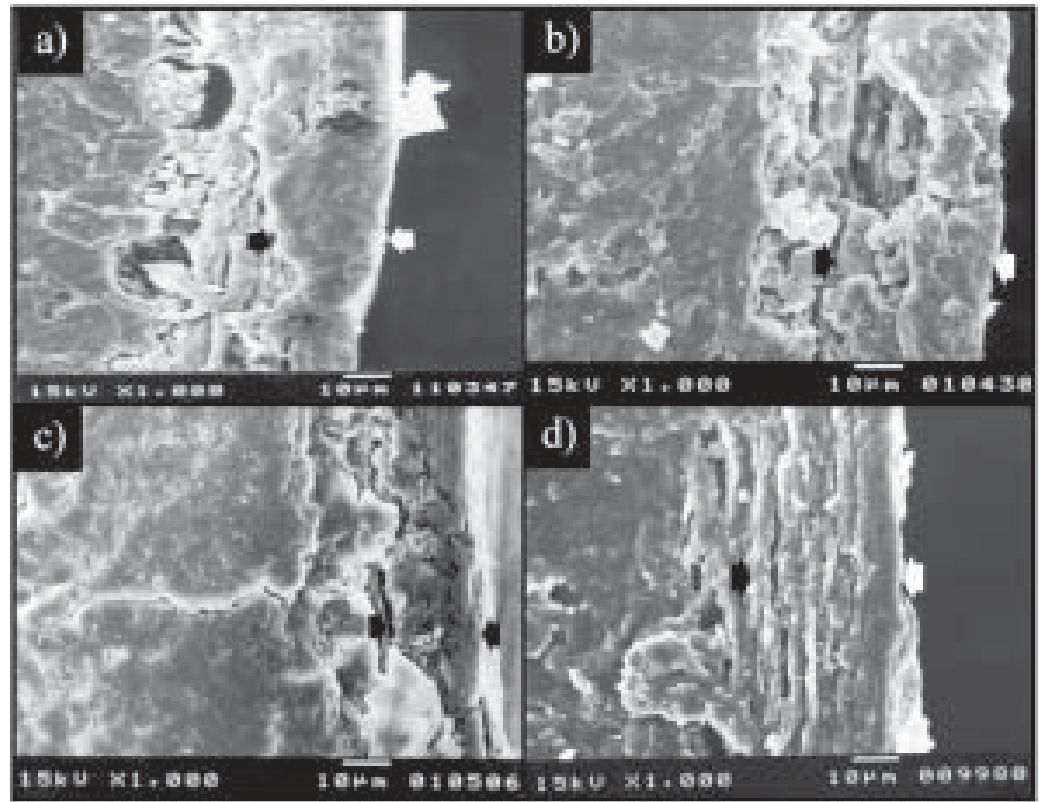

Figura 3. Eletromicrografias de varredura de cariopses de milho evidenciando a espessura do pericarpo $(\rightarrow)$ : a) linhagem dentado suscetível; b) linhagem dentado resistente; c) linhagem flint suscetível; d) linhagem flint resistente. Barra $=10 \mu \mathrm{m}$. 


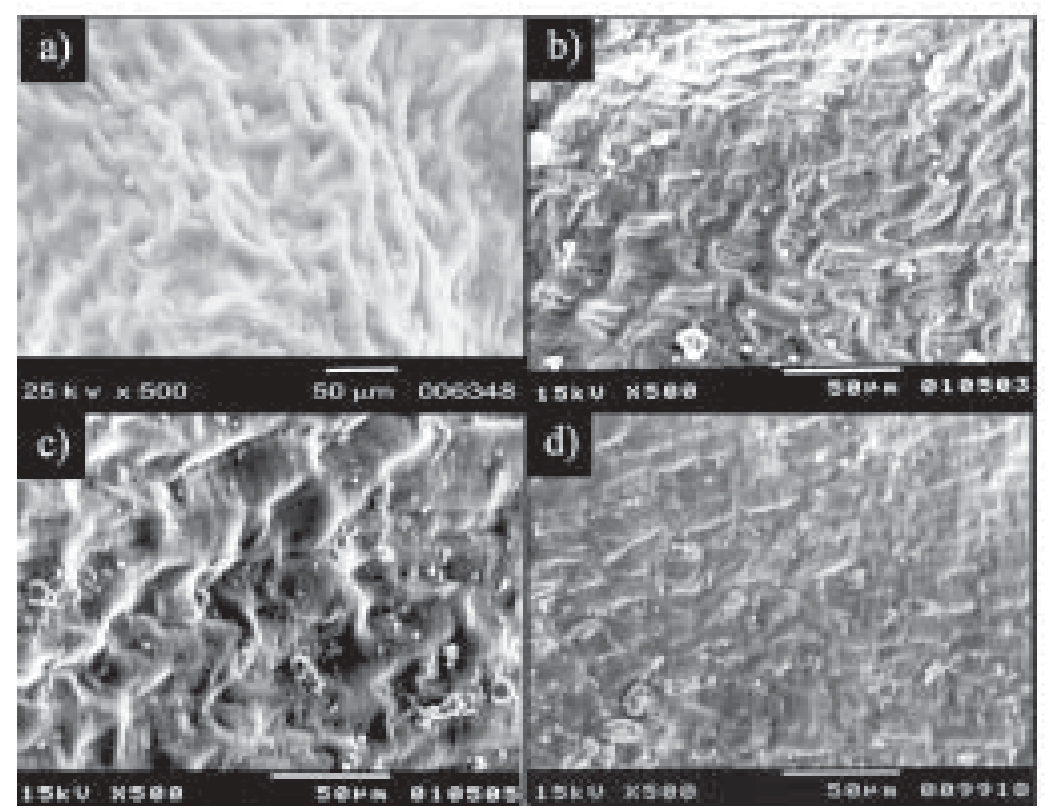

Figura 4. Eletromicrografias de varredura de cariopses de milho evidenciando o tegumento próximo da cicatriz do estilete: a) linhagem dentado suscetível; b) linhagem dentado resistente; c) linhagem flint suscetível; d) linhagem flint resistente. Barra $=50 \mu \mathrm{m}$.

Provavelmente, nas linhagens DS, DI e FS o tecido do pericarpo é mais frouxo, podendo ocorrer o rompimento da base do estilete no momento de cicatrização, com exposição do canal. Já nas linhagens DR, FI e FR esse tecido é mais rígido, não se rompe e, portanto, o canal não aparece na maioria das cariopses.

A alta incidência da infecção dos estiletes com F. moniliforme que, conseqüentemente, infecta as cariopses, sugere que a atividade dos fatores de resistência pode ser expressa nos estiletes, pericarpos e outros tecidos das cariopses (Munkvold et al., 1997).

Headrick et al. (1990) sugeriram que a condição dos estiletes pode interferir na resistência à infecção da cariopse por F. moniliforme. Scott \& King (1984), citados pelos mesmos autores, também sugeriram que a herança da resistência à podridão-daespiga causada por esse fungo está sob controle maternal e que pode ser atribuída ao genótipo do pericarpo ou dos estiletes.

Nas cariopses expostas ao fungo, documentadas na região do estilete, a penetração do fungo se dá via abertura do canal estilar (Figura 7).

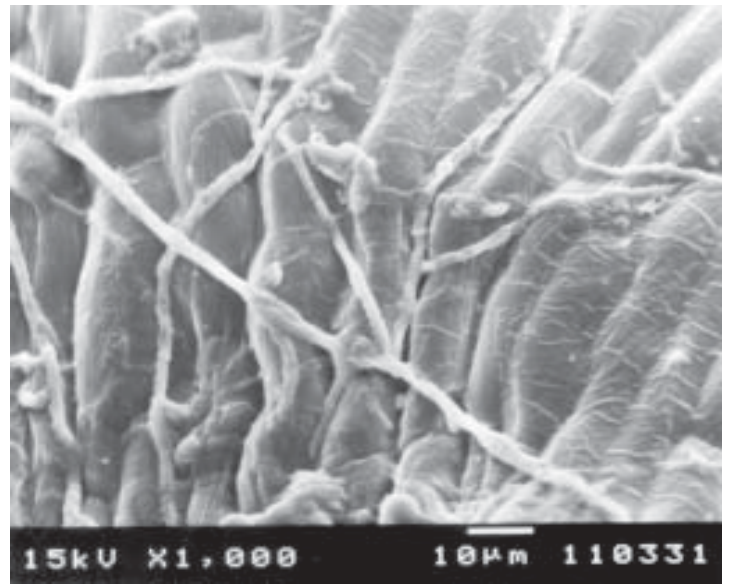

Figura 5. Eletromicrografia de varredura de cariopses de milho evidenciando hifas do fungo no tegumento da linhagem dentado suscetível. Barra $=10 \mu \mathrm{m}$.

De acordo com Kaiser (1980), citado por Nelson (1992), a penetração da hifa fúngica no interior da cariopse ocorre mediante orifícios e fissuras na su- 


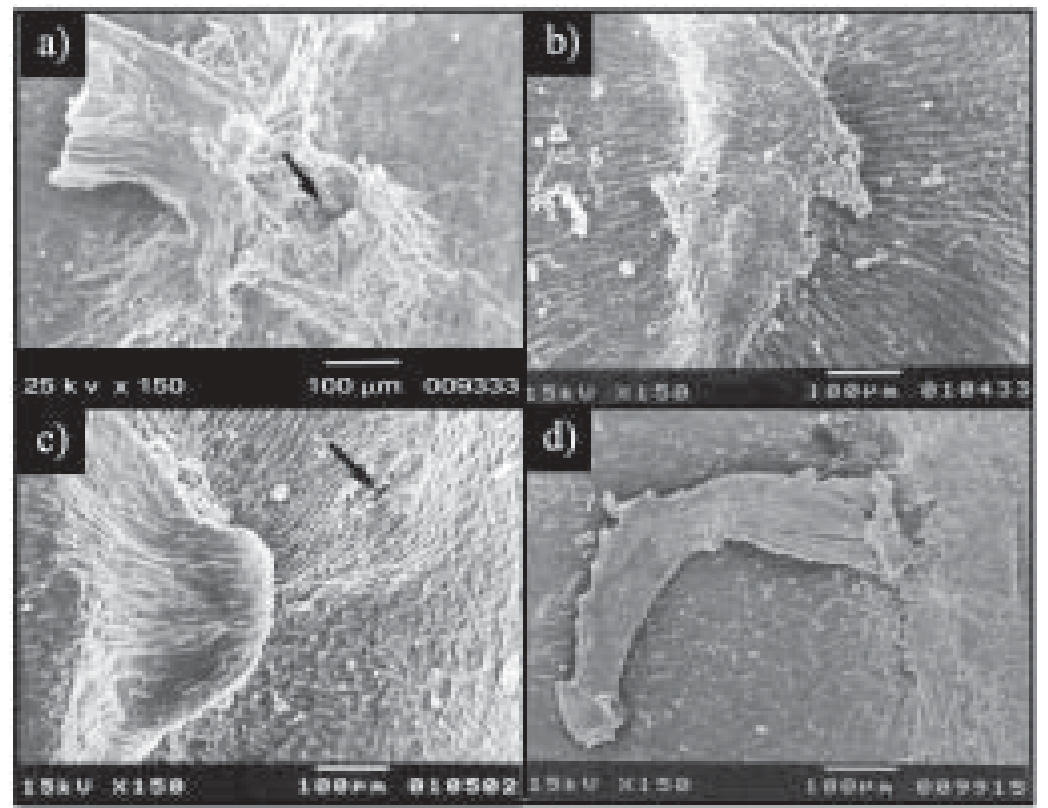

Figura 6. Eletromicrografias de varredura de cariopses de milho evidenciando presença da abertura da cicatriz do estilete $(\rightarrow$ ) nas linhagens dentado e flint suscetíveis (a e c, respectivamente) e ausência nas linhagens dentado e flint resistentes (b e d, respectivamente). Barra $=100 \mu \mathrm{m}$.

perfície do pericarpo, onde as hifas fúngicas se ramificam, entrando e crescendo no interior da cariopse, e através de pontos onde o pericarpo tinha sido rompido pela emergência da plântula. Desta maneira, ou o micélio teve acesso direto aos tecidos do embrião ou as hifas cresceram dentro de concavidades e depressões no tecido pedicelar.

A observação de que a abertura do canal estilar varia entre genótipos de milho, após o pleno desenvolvimento das cariopses, e que essas diferenças têm relação com a resistência ou suscetibilidade ao F. moniliforme, abre perspectivas de novos estudos nessa área. Assim, com base nessas constatações, será possível estabelecer metodologia para a seleção genética quanto a resistência à infecção das cariopses de milho pelo F. moniliforme.

Como o fungo penetra por aberturas do pericarpo e pela cicatriz do canal estilar, que têm controle genético, essas características podem ser usadas como critério de seleção. No entanto, para se utilizar a compactação do endosperma como critério de sele-

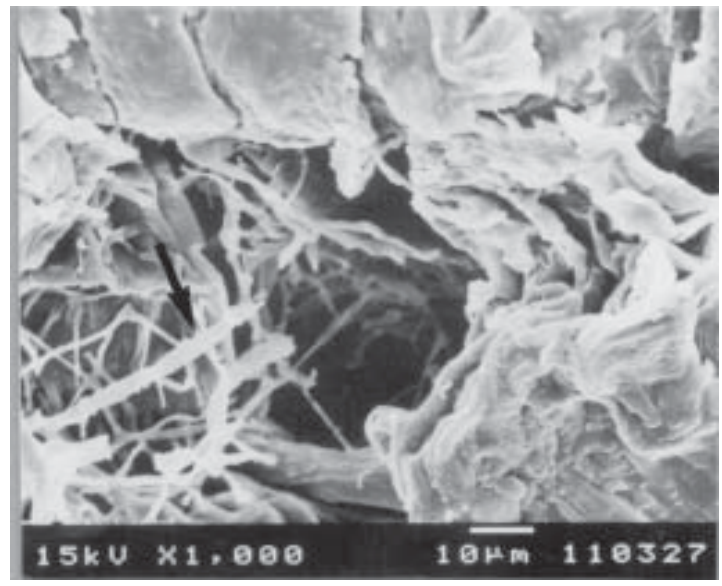

Figura 7. Eletromicrografia de varredura de cariopse de milho evidenciando a abertura da cicatriz do estilete com hifas do fungo penetrando $(\rightarrow)$. Linhagem dentado suscetível. Barra $=10 \mu \mathrm{m}$.

ção deve-se considerar também a preferência de mercado em relação a essa característica. 


\section{Conclusão}

As características morfológicas das cariopses que favorecem a penetração de Fusarium moniliforme são superfície do pericarpo com saliências e reentrâncias acentuadas, pericarpo pouco espesso, amido menos compacto e abertura do canal estilar.

\section{Referências}

FANCELLI, A. L.; DOURADO NETO, D. Produção de milho. Guaíba: Agrishow Agropecuária, 2000. 360 p.

HEADRICK, J. M.; PATAKY, J. K.; JUVIK, J. A. Relationships among carbohydrate content of kernels, condition of silks after pollination, and the response of sweet corn inbred lines to infection of kernels by Fusarium moniliforme. Phytopathology, St. Paul, v. 80, p. 487-494, 1990.

HOENISCH, R. W.; DAVIS, R. M. Relationship between kernel pericarp thickness and susceptibility to fusarium ear rot in field corn. Plant Disease, St. Paul, v. 78, p. 517519, 1994.
KUCHAREK, T. A.; KOMMEDAHL, T. Kernel infection and corn stalk rot caused by Fusarium moniliforme. Phytopathology, St. Paul, v. 56, p. 983-984, 1966.

MUNKVOLD, G. P.; DESJARDINS, A. E. Fumonisins in maize. Can we reduce their occurrence? Plant Disease, St. Paul, v. 81, n. 6, p. 556-565, 1997.

MUNKVOLD, G. P.; McGEE, D. C.; CARLTON, W. M. Importance of different pathways for maize kernel infection by Fusarium moniliforme. Phytopathology, St. Paul, v. 87, n. 2, p. 209-217, 1997.

NELSON, P. E. Taxonomy and biology of Fusarium moniliforme. Mycopathology, Dordrecht, v. 117, p. 29-36, 1992.

PEREIRA, O. A. P. Doenças do milho. In: KIMATI, H.; GALLI, F. (Ed.). Manual de fitopatologia: doenças das plantas cultivadas. São Paulo: Agronômica Ceres, 1997. v. 2, p. 87-101.

PINTO, N. F. J. de A. Patologia de sementes de milho. Sete Lagoas: Embrapa-CNPMS, 1998. 44 p. (Circular Técnica, 29). 